\title{
ESTIMATION OF SOME POSTHARVEST LOSSES IN TOMATO DURING SIMULATED TRANSPORT OPERATION
}

\section{Ghazal $^{*}$ A. F., El-Masry ${ }^{* *}$ G. M., El-Sheikh ${ }^{* *}$ I. H. and Radwan ${ }^{* * *}$ S. M ABSTRACT}

This study was conducted to estimate the extent of the damage occurred in tomato crop during transportation. A simulation prototype for transport process was designed and five levels of vibration frequency (5, $7.5,10,12.5$ and $15 \mathrm{~Hz}$ ), three vibration durations (30, 60, $90 \mathrm{~min})$ and three box positions (top, middle and bottom) were used to estimate the mechanical damage occurred in tomato fruits. The damage was evaluated based on three different parameters (damage ratio, the equivalent bruise index "EBI" and bruise area index "BAI"). Also, the effect of the studied variables was investigated on weight loss and firmness. The results revealed that damage ratio, EBI, BAI and weight losses increased and firmness values decreased by increasing vibration duration especially in the upper boxes for all vibration frequency levels. The results showed that the highest values of damage ratio, EBI, BAI and weight losses and the lowest value of firmness were recorded at the upper box when the simulation system was operated at vibration frequency of $7.5 \mathrm{~Hz}$ for a duration of $90 \mathrm{~min}$ compared to the other frequency levels. The information obtained from this study is very important when designing handling equipment, suspension systems, conveyor belts and packaging methods to reduce mechanical damages of fruits and vegetables.

Keywords: Postharvest losses, tomato, vibration, firmness, mechanical damage, equivalent bruise index, bruise area index.

\section{INTRODUCTION}
7 he success of a postharvest system encompasses delivering of crops from the place and time of harvest to the place and time of consumption with maximum efficiency, minimum losses and maximum profit.

\footnotetext{
"Demonstrator, ${ }^{* *}$ Associate Prof., ${ }^{* * * *}$ Prof. of Agric. Eng., Agric. Eng. Dept., Fac. of Agric., Suez Canal Univ.
} 
Actually, fresh products go through a number of steps in the handing chain such as transportation, cleaning, sorting, classification, packing, weighing, labeling and sealing to enhance their attractiveness before being shipped to the retail stores. Throughout these steps, agricultural products are usually liable to several kinds of losses. This loss may be quantitative losses such as a loss in the product quantity, or qualitative losses such as a loss in nutritional and caloric value, edibility and consumer acceptability to the products. These kinds of losses are much more difficult to assess than quantitative losses (Kader, 2005).

Postharvest loss has been defined as any change in the availability, edibility and wholesomeness or quality of food that prevent it from being eaten by human (Vursavuş \& Özgüven, 2004). In some situation, postharvest losses averaged between 24 and $40 \%$ in developing countries and between 2 and $20 \%$ in developed countries (Rosa, 2006). In tomato, the largest percentage of postharvest losses was due to mechanical damage caused by impact, compression, abrasion, puncturing, testing, or several actions combined (Li \& Thomas, 2014). Symptoms such as cuts, punctures, abrasions, scuffing, and brown discoloration of bruised tissues predisposed the product to accelerate water loss and to be attacked by various pathogens. These symptoms may not be visible at shipping point, but become noticeable during subsequent handling steps, and have a cumulative effect with each step of the handling process. Therefore, it is important to understand the nature of the shocks and vibrations encountered during truck transport to reduce damage to transported goods (Lu et al., 2010).

One of the mechanical handling processes that can be detrimental to the quality of the fruit is transportation. In general, unreasonable transportation is the one of main factors that causes losses in fruits and vegetables (Lü $\boldsymbol{e t ~ a l . , ~ 2 0 1 0 ) . ~ P o s t h a r v e s t ~ l o s s e s ~ o f ~ t o m a t o ~ d u r i n g ~ t r a n s p o r t ~}$ process were estimated to be about 16 - $22 \%$ (Bani et al., 2006). The results of studies investigated the in-transit damage indicated that vibration damage occurs in the fruits and the extent of such bruising is related directly to the magnitude of vibration accelerations and to the frequency (Timm et al., 1996; Vursavuş \& Özgüven, 2004). The 
magnitude of vibration acceleration during transport depends on the depth to which the container is filled, the tightness of fill, the type of suspension system used on the truck, the magnitude of forced vibration from the roadbed and the vibrating characteristics of the fruit species. In general, the three types of forces that may cause bruising in fruits are impact, compression load and vibration forces (Rostampour et al., 2013). Vibration forces that usually occur during transportation are difficult to avoid and can be repeated five to fifteen times each second for many hours of the trip (Vergano et al., 1991).

In Egypt, farmers transport their products in medium sized trucks after packaging in palm crates. Rough handling and transportation over Egyptian roads damaged produces by mechanical action resulting in a substantial reduction in quality. A large percentage of fruits are wasted yearly due to damages such as bruising caused mostly by impact during handling, packaging, and transport of fruits (Amer Eissa \& Azam, 2011). If damage occurs, economic losses might be minimized by grading damaged fruits based on the severity of damage into different categories. Moreover, damaged fruits could be directed to processing rather than fresh consumption. In either case, an objective and quantitative evaluation of the degree of mechanical damage is required. Ideally, such damages could be minimized through improved understanding of their mechanisms. Therefore, the main goal of this study was to estimate the extent of the damage occurred in tomato crop during transportation process. To fulfill this goal, the following sub-objectives were considered:

(1) Designing a transport prototype to control the vibration frequencies and vibration duration, (2) Studying the effect of different vibration frequency levels $(5,7.5,10,12.5$ and $15 \mathrm{~Hz})$, vibration duration (30, 60 and $90 \mathrm{~min}$ ) and box position (top, middle and bottom) on the severity of the mechanical damage occurred in the tomato fruits expressed as damage ratio, EBI and BAI and their effect on weight loss and tomato firmness, (3) Determining the critical vibrational frequency level and vibration duration that cause the least possible damage on tomato fruits and the least weight loss and firmness, and (4) Determining the effect of box 
position above the truck floor on the severity of the damage, firmness and weight losses of tomato.

\section{MATERIALS AND METHODS}

\subsection{Tomato Samples}

Fresh tomato samples (Solanum lycopersicum var. El-kudds 448) free from bruises and any visible damages were manually harvested daily from the experimental farm of the Faculty of Agriculture, Suez Canal University (Ismailia, Egypt) at the light red maturity stage during the period from December to March 2015. A random sample of 200 tomatoes was taken and the mass, firmness, total soluble solids and dimensions of each tomato were determined.

Due to the huge amount of tomato fruits required to carry out all experiments of this study, using large boxes $(21 \times 20 \times 17 \mathrm{~cm})$ usually used in transporting tomatoes was not feasible. Therefore, special small boxes made from crates and having the same features but with smaller dimensions were manually fabricated from crates. The box dimensions were chosen based on the average dimensions of the harvested tomato cultivar to accommodate only 27 tomatoes per box arranged in three layers.

Because tomato fruits were liable to scratching during the manual measurement of dimensions using the digital caliper, and due to human error during recording the data, this manual method may not be an efficient or practical approach to estimate dimensions, particularly in sorting large quantities of fruits (Sadrnia et al., 2007). Therefore, image processing method provides an accurate, simple, and rapid method to estimate the dimensions. So, the maximum, intermediate diameter, perimeter and projected area of tomato were measured using an image system (Figure 1). A colour image of each tomato was captured by an imaging system and processed to extract the dimensions directly from the images without holding fruits by hands. All image analysis routines were carried out by a script developed using Matlab7.1 and its image processing toolbox (Mathworks, MA, USA). 


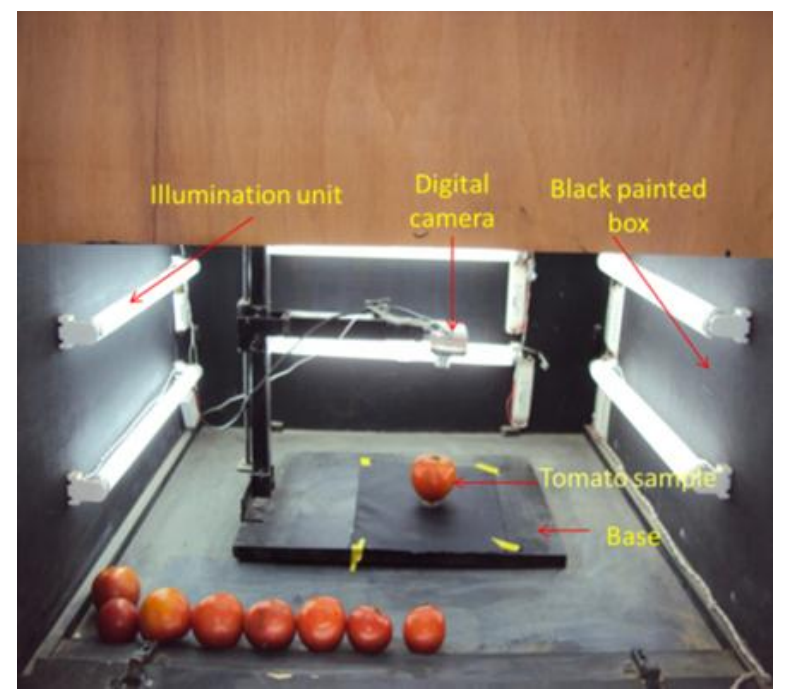

Figure (1): The image acquisition unit.

\subsection{Transport Prototype}

A prototype was designed and fabricated to simulate the transport process during marketing and moving the products from fields to the big markets or retail stores. The purpose was to identify the critical frequencies during transportation that cause minimum damage to the product. Also, the box position above the truck was evaluated. The simulation prototype (Figure 2) was designed and constructed in the workshop of the Department of Agricultural Engineering, Faculty of Agriculture, Suez Canal University. The prototype composed of a main frame $(110 \times 70 \times 81 \mathrm{~cm})$ which holds the other parts including a power supply, steel spring (with stiffness 20 $\mathrm{N} / \mathrm{mm}$ ), and vibration surface. The power required to move the vibration surface was transmitted by a V-shape belt and two pulleys as shown in Figure (2). The rotation speed of the motor, vibrator and vibration surface was adjusted and controlled by an inverter (model 650G, Parker, U.K).

As shown in Figure (2), the vibration unit consists of a vibrator, comprised of a shaft that contains a longitudinal cam connected with a pulley. When this shaft rotates, a vibration motion is generated to the surface of the vibrator as a result of centrifugal force when the cam rotates. The vibration surface holds on steel springs for damping vibration intensity to some extent as it happens in the transport vehicles. 

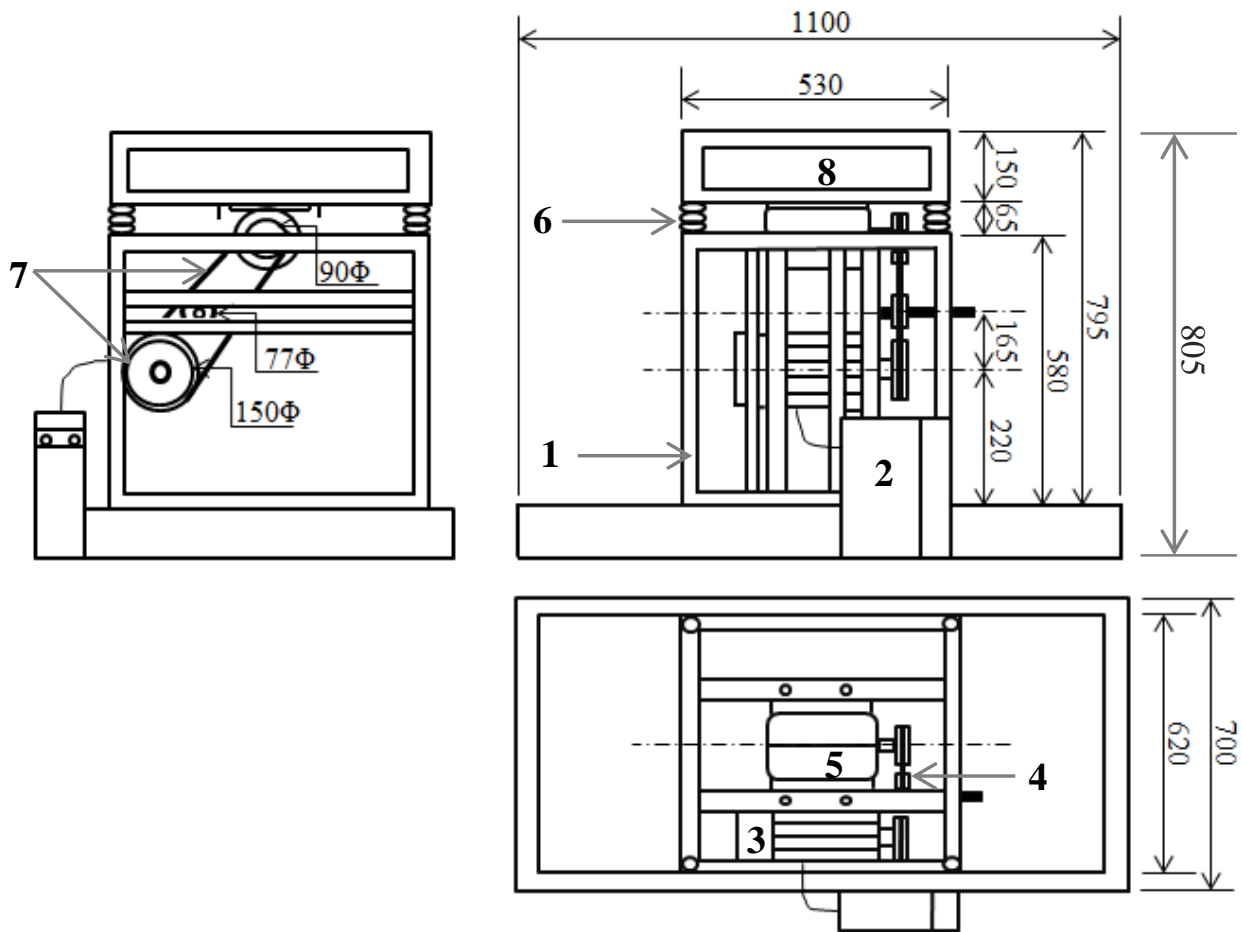
(1) Main frame
(2) Inverter
(3) Electric motor
(4) Tensile pulley

(5) Vibrator

(6) Steel spring

(7) Belt and pulleys

(8) Vibration surface

Figure (2): Elevation, side and plan views of the designed simulation prototype.

\subsection{Measurement of Vibration}

Because the frequency of the vibration surface is directly related to the rotation number of the vibrator, the frequency of the vibration surface was obtained based on the number of revolutions of the vibrator. Therefore, the speed of the electric motor and the vibrator were measured using a digital Tachometer (Model DT06234N, China, Accuracy $\pm 0.1 \%$ ). The number of the revolutions of vibrator measured in revolution per minutes RPM was divided by 60 to get the vibration frequency of vibration surface in $\mathrm{Hz}$ and this value was confirmed by measuring the frequency of vibration surface using a digital Tachometer. The acceleration of the vibration surface was directly measured using a vibration meter (VB8220, Lutron, Taiwan). The vertical displacement (stroke) of vibration 
was calculated by the following equation (1) according to Rostampour $\boldsymbol{e t}$ al. (2013):.

$$
A=4 \pi^{2} f^{2} x
$$

where, $A$ is the acceleration $\left(\mathrm{m} / \mathrm{s}^{2}\right), f$ is the frequency $(H z)$ and $x$ is the displacement amplitude $(m)$.

According to Vursavuş \& Özgüven (2004) and Shahbazi et al. (2010) the highest value of distribution percentages of vibration frequencies on the truck-beds were at intervals of $5-10 \mathrm{~Hz}$ and $10-15 \mathrm{~Hz}$. Therefore, vibrational frequencies of values from 5 to $15 \mathrm{~Hz}$ with an interval of 2.5 $\mathrm{Hz}$ were selected for testing vibration effect.

To understand the reasons for in-transit injury of various fruits due to vibration, it is necessary to determine the natural frequency and relate these to the vibration characteristics of the transporting vehicles. Therefore, the natural frequency was calculated by using the following equation (2) according to Mohsenin (1986).

$$
f_{n}=\frac{1}{4 \lambda} \sqrt{\frac{E g}{\rho_{b}}}
$$

where: $f_{n}$ : natural frequency $(\mathrm{Hz}), g: 9.81 \mathrm{~m} / \mathrm{s}^{2}, \rho$ : bulk density $\left(\mathrm{kg} / \mathrm{m}^{3}\right)$, and $\lambda$ : depth of column of fruit $(m)$. E: elasticity $\left(\mathrm{kg} / \mathrm{m}^{2}\right)$ was calculated according to equation of Ghazavi et al. (2012) as:

$$
E=\frac{F_{\max }}{D_{p}} \times \frac{1-\mu^{2}}{2 r}
$$

where: $E$ : Elasticity modulus $(M p a), F_{\max }$ : Maximum applied force (firmness) $(N), D_{p}$ : Probe penetration inside the sample $(\mathrm{mm}), \mu$ : Poisson ratio $(0.3), r$ : Probe radius $(\mathrm{mm})$.

\subsection{Experimental Protocol}

Tomato samples were collected at a homogeneous harvesting stage and carefully inspected to ensure that they were neither damaged, diseased nor infected. Tomato fruits were then divided into four groups in which one 
group was assigned as a control. Three groups of tomato fruits were placed inside boxes (27 fruits per in each box. Then, the boxes (top, middle and bottom) were placed on vibration simulation prototype to conduct a treatment. After operating the prototype at every level of vibration frequency and vibration duration, tomato samples were taken out from the boxes and examined to evaluate the level of damage.

After each vibration treatment (frequency level and duration), a digital caliper was used to measure bruise diameter on the tomato surface and tomatoes were graded according to their bruise diameter as described by Vursavuş \& Özgüven (2004) as shown in Table (1) and the equivalent bruise index (EBI) for defining the damage occurred in tomato fruits was calculated as:

$\% \mathrm{EBI}=(0.1)$ Trace bruises $+(0.2)$ Slight bruises $+(0.7)$ Medium bruises + (1.0) Severe bruises.

Table (1): Damage scale by using the bruise diameter.

\begin{tabular}{c|c|c}
\hline \hline $\begin{array}{c}\text { Bruise diameter } \\
(\mathbf{m m})\end{array}$ & \multicolumn{2}{|c}{ Type of damage or } \\
Equivalent bruise damage (EBI)
\end{tabular}

The ratio between the number of tomatoes having bruise damage greater than $12 \mathrm{~mm}$ in diameter $\left(\mathrm{N}_{\mathrm{d}}\right)$ to the total number of tomatoes $\left(\mathrm{N}_{\mathrm{T}}\right)$ in the treatment (27 fruits) is called the damage ratio and calculated as follow:

$$
\text { Damage ratio }=\frac{N_{d}}{N_{T}} * 100 \quad,(\%)
$$

Also, the bruise area (BA) was determined by measuring the bruise diameter on the tomato surface and assuming that the bruise was elliptical. The BA was calculated by the following equation (Lu et al., 2010):

$$
B A=\frac{\pi}{4} d_{0} * d_{1}
$$


where: $B A$ is bruised area $\left(\mathrm{mm}^{2}\right), d_{0}$ and $d_{1}$ are the major and minor diameters of a bruise respectively ( $\mathrm{mm}$ ).

The extent of the bruising area in tomato was expressed as bruising area index (BAI), which was determined by using a four stage scale $(0,1,2$ and 3 ), where $0=$ none, $1=$ slight ( $<20 \%$ of surface area), $2=$ moderate (20 to $50 \%$ of surface area), and $3=$ severe $(>50 \%$ of surface area) as described by Jing et al. (2009) and Cao et al. (2010).

Bruising area index (between 0 and 3 )

\subsection{Fruit Firmness}

$$
=\frac{\sum(\text { scale } \times \text { number of fruit at that scale })}{\text { total number of fruit in the treatment }}
$$

Firmness of each single tomato fruit was measured to show the effect of different vibration levels, vibration durations and box position on tomato properties. Firmness was determined by resistance to puncture using a fruit firmness tester (Affegi penetrometer, FT- 011Model, Italy, Accuracy $\pm 0.05 \% \mathrm{~kg}$ ) at two different places of each tomato fruit after removing the peel (Batu, 1998). About $1 \mathrm{~cm}^{2}$ area of the peel was removed very carefully and the maximum force required penetrating the fruit with a 6 $\mathrm{mm}$ diameter round stainless steel probe was recorded.

\subsection{Weight Losses}

Weight losses were determined by measuring the initial weight of tomatoes before a vibration treatment $\left(\mathrm{W}_{1}\right)$ and after 48 hours from the vibration treatment $\left(\mathrm{W}_{2}\right)$ using a digital balance then calculate the weight losses from the following equation according to Van Dijk $\boldsymbol{e t}$ al. (2006) and compared with the weight losses of control samples caused by evaporation from the surface of the fruit:

\subsection{Statistical Analysis}

$$
\text { Weight losses }=\frac{W_{1}-W_{2}}{W_{1}} * 100 \quad,(\%)
$$

About 0.61 tons (3645 fruits) of tomatoes were used for carrying out all vibration, duration and position treatment combinations of this experiment. Three replicates at every combination of the experimental factors were used (every replicate consisted of 27 tomatoes). The experimental design for this work was a randomized block design. 
The obtained data were subjected to statistical analysis using CoStat 6.4 (CoStat, USA) and the analysis of variance (ANOVA) was conducted in order to ascertain whether there were any significant differences among the vibration frequency levels, box positions and vibration durations on damage parameters, firmness and weight losses of tomato at the significance level of 0.05 . Furthermore, the least significant difference (LSD) test was performed to compare the effects of these variables and their interactions on damage parameters (damage ratio, EBI and BAI), weight losses and firmness of tomatoes.

\section{RESULTS AND DISCUSSION}

\subsection{Dimensional features}

As shown in Table (2), the mean values of the maximum and intermediate diameters as well as projected area of the examined samples were tomato were $68.59,64.91 \mathrm{~mm}$ and $35.25 \mathrm{~cm}^{2}$, respectively. Table (2) shows the imaging technique gave a good estimation of the measured dimensions and could be used directly without touching or holding every sample during measurements.

Table (2): Geometrical features of tomato measured by a digital caliper and the image analysis technique.

\begin{tabular}{||c|c|c|c|c|c|c||}
\hline \multirow{2}{*}{ Dimensions } & \multicolumn{3}{|c|}{ Digital caliper } & \multicolumn{3}{|c||}{ Image analysis } \\
\cline { 4 - 7 } & Min & Max & Mean \pm S & Min & Max & Mean \pm S \\
\hline $\begin{array}{c}\text { Maximum } \\
\text { Diameter, } \\
\text { mm }\end{array}$ & 53.17 & 81.56 & $68.59 \pm 6.84$ & 52.34 & 84.18 & $68.8 \pm 8.86$ \\
\hline $\begin{array}{c}\text { Intermediate } \\
\text { Diameter, } \\
\text { mm }\end{array}$ & 52.65 & 76.22 & $64.91 \pm 6.05$ & 50.90 & 78.50 & $65.28 \pm 8.02$ \\
\hline $\begin{array}{c}\text { Projected } \\
\text { Area, cm }\end{array}$ & 21.98 & 48.05 & $35.25 \pm 6.56$ & 18.33 & 53.62 & $36.92 \pm 98.87$ \\
\hline
\end{tabular}

\subsection{Influence of Simulated Transport on Mechanical Damage}

The next sections demonstrate the influence of the main variables (vibration frequency "VF", vibration duration "VD", and box position "BP") separately, second-order interaction between vibration frequency and both of vibration duration $(\mathrm{VF} \times \mathrm{VD})$ and box position $(\mathrm{VF} \times \mathrm{VD})$ as 
well as the third-order interaction between vibration frequency, vibration duration and box position $(\mathrm{VF} \times \mathrm{VD} \times \mathrm{BP})$ on mechanical damage (damage ratio, EBI and BAI), weight losses and firmness of tomatoes.

The analysis of variance results given in Table (3) showed that vibration frequency (VF), vibration duration (VD) and box position (BP) significantly affected the damage ratio, EBI and BAI values of tomatoes. The effects of the main factors are highly significant on damage ratio, EBI and BAI, and the interaction effects of the $(\mathrm{VF} \times \mathrm{VD}),(\mathrm{VF} \times \mathrm{BP})$, $(\mathrm{VD} \times \mathrm{BP})$ and $(\mathrm{VF} \times \mathrm{VD} \times \mathrm{BP})$ were significant on $\mathrm{EBI}$ and weight losses values $(\mathrm{P} \leq 0.05)$. However, the interaction effects of the $(\mathrm{VF} \times \mathrm{BP})$, $(\mathrm{VD} \times \mathrm{BP})$ and $(\mathrm{VF} \times \mathrm{VD} \times \mathrm{BP})$ were not significant on damage ratio values, and the interaction effects of the $(\mathrm{VF} \times \mathrm{VD} \times \mathrm{BP})$ were not significant on $\mathrm{BAI}$ values $(\mathrm{P} \leq 0.05)$. Also, the interaction effects of the $(\mathrm{VD} \times \mathrm{BP})$ were not significant on firmness values $(\mathrm{P} \leq 0.05)$.

Table (3): Statistical analysis results for damage ratio, EBI, BAI, weight losses in tomato fruits. Values reported in this table are the $\mathrm{F}$ table of the analysis of variance (ANOVA) for each variable.

\begin{tabular}{|c|c|c|c|c|c|c|}
\hline $\begin{array}{l}\text { Source of } \\
\text { variance }\end{array}$ & df. & $\begin{array}{c}\text { Damage } \\
\text { ratio }(\%)\end{array}$ & $\begin{array}{l}\text { EBI } \\
(\%)\end{array}$ & BAI & $\begin{array}{c}\text { Weight } \\
\text { losses (\%) }\end{array}$ & $\begin{array}{c}\text { Firmness } \\
(\mathbf{N})\end{array}$ \\
\hline $\begin{array}{l}\text { Vibration } \\
\text { frequency } \\
\text { (VF) }\end{array}$ & 4 & $103.3095 * * * *$ & $99.6984 * * *$ & $82.8706 * * *$ & $96.1737 * * *$ & $422.0104 * * *$ \\
\hline $\begin{array}{c}\text { Vibration } \\
\text { Duration } \\
\text { (VD) }\end{array}$ & 2 & $40.1649 * * *$ & $56.9935 * * *$ & $55.9067 * * *$ & $62.5227 * * *$ & 140.4635 *** \\
\hline $\begin{array}{c}\text { Box Position } \\
\text { (BP) }\end{array}$ & 2 & 34.7195**** & $61.4860 * * *$ & $43.5065 * * *$ & $39.1460 * * *$ & 167.2930 **** \\
\hline$V F \times V D$ & 8 & $3.1683 * *$ & $11.1929 * * *$ & $8.4012 * * *$ & $18.4363 * * *$ & $12.4473 * * *$ \\
\hline$V F \times B P$ & 8 & $2.0415^{\mathrm{NS}}$ & $6.6275 * * *$ & $4.4639 * * *$ & $9.5453 * * *$ & $8.0417 * * *$ \\
\hline$V D \times B P$ & 4 & $0.53911^{\text {NS }}$ & $5.3779 * * *$ & $3.0140 *$ & $3.4877 *$ & $1.7190^{\mathrm{NS}}$ \\
\hline $\mathrm{VF} \times \mathrm{VD} \times \mathrm{BP}$ & 16 & $1.1218^{\mathrm{NS}}$ & $2.3741 *$ & $1.9188^{\mathrm{NS}}$ & $2.5127 * *$ & $1.9034 *$ \\
\hline Error & 88 & - & - & - & - & - \\
\hline
\end{tabular}

NS: not significant at 0.05 level of probability.

$*, * *, * * *$ : significant differences at 0.05 level of probability.

Generally, vibration can continuously cause damages to the fruits that may be duplicated with time. Thus, using the laboratory vibration 
prototype under controlled conditions is very important to expect the effect of transportation during handling processes. Effects of vibration frequency levels, vibration durations and box position on mechanical damage of tomato during transport process will be discussed in the subsequent sections.

\subsubsection{Effect of Vibration Frequency}

The results shown in Table (4) present the damage ratio, EBI and BAI values observed in tomato during simulated transport of different vibration frequency. The damage ratio was $8.60,20.80,16.27,9.14$ and $18.11 \%$ at vibration frequency of $5,7.5,10,12.5$ and $15 \mathrm{~Hz}$, respectively. The results indicated that the EBI and BAI values in tomato were 2.24, 9.74, 5.81, 2.36 and $6.50 \%$ and $0.41,1.01,0.73,0.40$ and 0.83 at vibration frequency of $5,7.5,10,12.5$ and $15 \mathrm{~Hz}$, respectively. This means that the highest values of damage ratio, EBI and BAI in tomato $(20.80 \%, 9.74 \%$ and 1.01$)$ were observed at the vibration frequency of $7.5 \mathrm{~Hz}$. The result for damage ratio and EBI are in agreement with those reported by Shahbazi et al. (2010) and Vursavuş \& Özgüven (2004), respectively. This is may be due to the high acceleration and maximum displacement at this level. The results obtained from the measurement of acceleration and displacement at every level of vibration frequency showed that the acceleration was 2.00, 11.50, 7.30, 6.00 and $8.40 \mathrm{~m} / \mathrm{s} 2$ and the displacement was $4.05,10.35,3.7,1.94$ and $1.89 \mathrm{~mm}$ at vibration frequency of 5, 7.5, 10, 12.5 and $15 \mathrm{~Hz}$, respectively as shown in Figure (3).

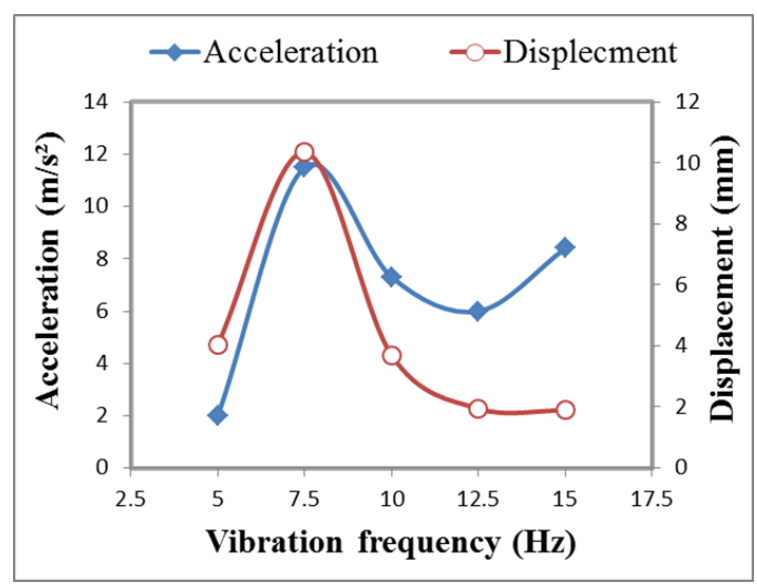

Figure (3): The relationship between the vibration frequency and vibration displacement or vibration acceleration during the simulation test. 
These results revealed that the highest acceleration occurred at the vibration frequency of $7.5 \mathrm{~Hz}$ because this level made the surface of the vibration to reach the maximum displacement in terms of force and speed (vibration frequency). Increasing the speed of vibration (vibration frequency) led to a decrease in the displacement significantly and an increase in the vibration acceleration. On the other hand, the force of vibration at the vibration frequency of $5 \mathrm{~Hz}$ was not enough to reach the maximum displacement. Therefore, when combining the vibration frequency value and displacement value according to equation (1), the highest acceleration occurred at vibration frequency of $7.5 \mathrm{~Hz}$ and the lowest acceleration occurred at vibration frequency of $5 \mathrm{~Hz}$. According to O'Brien \& Bridley (1970), this high acceleration makes some fruits momentarily weightless and free to strike other fruits, causing high damage.

If forced frequency is equal to the natural frequency called resonance frequency and according to Shahbazi et al. (2010), if the resonance frequency of the fruit column is the same as the excitation frequency of the vehicle or road, the acceleration of the fruit can be considerably increased due to the resonance, and a severe damage may occur. The result shows that the natural frequency of tomato was $22.16 \mathrm{~Hz}$ according to equation (2). This result is closed to those reported by O'Brien $\boldsymbol{e t} \boldsymbol{a l}$. (1965). This result explain the reason of increasing the severe damage and convert the fruit to juice at a vibration frequency of $25 \mathrm{~Hz}$ in the preliminary experiments as a result of its proximity to natural frequency.

Fruit firmness is one of the most important mechanical properties to determine the tomato quality and can be used as an index to estimate and manage the damages because it expresses the fruit resistance to penetration or the force needed to penetrate the fruit during handling operations. The original firmness of tomatoes varied from 18.39 to 39.84 $\mathrm{N}$ with an arithmetic mean value of $27.28 \mathrm{~N}$ with a coefficient of variation value of $17.94 \%$. 
Table (4): Overall mean values of damage ratio, EBI and BAI recorded in the fresh tomatoes at different vibration frequency levels, different vibration durations and box positions.

\begin{tabular}{|c|c|c|c|c|c|c|}
\hline \multicolumn{2}{|c|}{ Parameters } & \multirow{2}{*}{$\begin{array}{c}\begin{array}{c}\text { Damage } \\
\text { ratio } \\
(\%)\end{array} \\
\mathbf{8 . 6 9 d} *\end{array}$} & \multirow{2}{*}{$\begin{array}{l}\text { EBI } \\
(\%)\end{array}$} & \multirow{2}{*}{$\frac{\text { BAI }}{0.41^{\mathrm{d}}}$} & \multirow{2}{*}{$\begin{array}{c}\begin{array}{c}\text { Weight } \\
\text { losses } \\
(\%)\end{array} \\
2.77^{\mathrm{d}}\end{array}$} & \multirow{2}{*}{$\begin{array}{c}\text { Firmness } \\
(\mathbf{N}) \\
11.30^{\mathrm{a}}\end{array}$} \\
\hline & 5 & & & & & \\
\hline \multirow{4}{*}{ 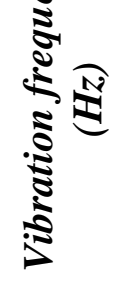 } & 7.5 & $20.67^{a}$ & $9.74^{\mathrm{a}}$ & $1.01^{\mathrm{a}}$ & $5.06^{a}$ & $8.25^{\mathrm{e}}$ \\
\hline & 10 & $16.27^{\mathfrak{c}}$ & $5.81^{b}$ & $0.73^{c}$ & $3.61^{c}$ & $9.81^{\mathrm{c}}$ \\
\hline & 12.5 & $9.15^{d}$ & $2.36^{c}$ & $0.40^{d}$ & 2.99d & $10.45^{b}$ \\
\hline & 15 & $17.97^{b}$ & $6.50^{b}$ & $\mathbf{0 . 8 3}{ }^{b}$ & $4.01^{b}$ & $9.43^{d}$ \\
\hline \multirow{3}{*}{ 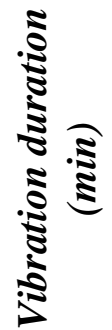 } & 30 & $12.04^{\mathrm{c} *}$ & $3.72^{\mathrm{c}}$ & $0.52^{c}$ & $3.22^{\mathrm{c}}$ & $10.25^{a}$ \\
\hline & 60 & $14.38^{b}$ & $4.99^{b}$ & $0.65^{b}$ & $3.51^{\mathrm{b}}$ & $10.02^{b}$ \\
\hline & 90 & $17.23^{\mathrm{a}}$ & $7.29 \mathrm{a}$ & $0.86^{a}$ & $4.32^{\mathrm{a}}$ & $9.28^{\mathrm{c}}$ \\
\hline \multirow{3}{*}{ 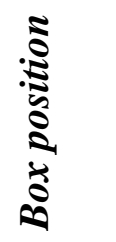 } & Top & $16.98^{a *}$ & $7.40^{\mathrm{a}}$ & $0.84^{a}$ & $4.19^{a}$ & $9.25^{\mathrm{c}}$ \\
\hline & Middle & $14.51^{b}$ & $4.86^{b}$ & $0.64^{b}$ & $3.54^{b}$ & $9.96^{b}$ \\
\hline & Bottom & $12.15^{\mathrm{c}}$ & $4.62^{\mathrm{c}}$ & $0.55^{\mathrm{c}}$ & $3.33^{c}$ & $10.34^{a}$ \\
\hline
\end{tabular}

* Same letters in the same column indicate no significant difference among corresponding treatments at a significant level of $P \leq 0.05$.

The results shown in Table (4) demonstrate that the weight losses and firmness values observed in tomato during simulated transport of different vibration frequency. The weight losses were 2.77, 5.06, 3.61, 2.99 and 4.01 and the firmness was $11.30,8.25,9.81,10.45$ and $9.43 \mathrm{~N}$ at the vibration frequency of $5,7.5,10,12.5$ and $15 \mathrm{~Hz}$, respectively. These results revealed that the highest value of weight losses in tomato $(5.06 \%)$ and the lowest value of tomato firmness $(8.25 \mathrm{~N})$ were recorded at the 
vibration frequency of $7.5 \mathrm{~Hz}$. This is may be ascribed to the high acceleration and maximum displacement at this level. According to Jung \& Park (2012), the vibration stress clearly accelerated the degradation of fruit quality, resulting in increased weight loss and decreased firmness.

Generally, weight losses during storage were expected owing to tomato transpiration. The results showed that weight losses increased after the vibration treatment compared to the control group that did not received any vibration stress. Tomato fruits treated by vibration (different frequencies or different duration) may have a higher respiration and mechanical damage therefore may experience more weight loss. Also, according to Idah et al. (2012), the opening of the bruised areas led to a release of moisture from the damaged fruits. This also exposed the fruits to infestation by other spoilage organisms accelerating the rate of decay. Those rotten fruits showed signs of shrinkage and this led to a decrease in the weight of tomato fruits.

Table (4) shows the least significant difference (LSD) tests performed to determine the differences among the mean values of the damage ratio, EBI, BAI, firmness and weight losses in the tomato at different vibration frequency levels. In general, there was a significant difference $(\mathrm{P} \leq 0.05)$ among vibration frequency levels on the values of damage ratio, EBI, BAI, firmness and weight losses. The LSD test showed that there was a significant difference between the effect of vibration frequency of 7.5, 10 and $15 \mathrm{~Hz}$ on damage ratio, BAI and weight losses value $(\mathrm{P} \leq 0.05)$. However, there is no significant difference between vibration frequency of 10 and $15 \mathrm{~Hz}$ in EBI value $(\mathrm{P} \leq 0.05)$. Furthermore, there is no significant difference between vibration frequency of 5 and $12.5 \mathrm{~Hz}$ in damage ratio, EBI, BAI and weight losses value $(\mathrm{P} \leq 0.05)$. However, there was a significant difference between the effect of vibration frequency of 5, 7.5, 10, 12.5 and $15 \mathrm{~Hz}$ on tomato firmness.

\subsubsection{Effect of Vibration Duration}

The results shown in Table (4) indicated that increasing the vibration duration led to increasing the damage ratio and the weight losses and this trend of result agrees with the findings reported by Fischer $\boldsymbol{e t}$ al. (1992) and Shahbazi et al. (2010). Also, increasing the EBI and BAI values with 
vibration duration is in agreement with Vursavuş \& Özgüven (2004) and decreasing of the tomato firmness value with vibration duration is in agreement with Demir et al. (2010). The damage ratio was 12.24, 14.49 and $17.01 \%$ when the vibration duration was 30, 60 and $90 \mathrm{~min}$, respectively. On the other hand, the EBI and BAI values were 3.72, 4.99 and $7.29 \%$ and $0.52,0.65$ and 0.86 when the vibration duration was 30 , 60 and $90 \mathrm{~min}$, respectively. Also, the weight losses were 3.22, 3.51 and 4.32 and fruit firmness were $10.25,10.02$ and $9.28 \mathrm{~N}$ when the vibration durations were 30, 60 and $90 \mathrm{~min}$, respectively. These results may be attributed to the fact that continuing vibration forces the fruits received and to strike each other and impacted during the entire vibration duration leading to increasing the damage ratio, EBI, BAI and weight losses and decreasing the firmness of the tomato fruits.

As indicated in the significant letters shown in Table (4), the LSD test revealed that the effects of the three vibration durations (30, 60 and 90 min) were significant on damage ratio, EBI, BAI, weight losses and firmness values $(\mathrm{P} \leq 0.05)$.

\subsubsection{Effect of Box Position}

The results shown in Table (4) indicated that the damage ratio in tomato was $16.92,14.57$ and $12.23 \%$, the EBI values were $7.40,4.86$ and 4.62 $\%$, the BAI values were $0.84,0.64$ and 0.55 , the weight losses were 4.19 , 3.54 and 3.33 and the firmness values were 9.25, 9.96 and $10.34 \mathrm{~N}$ at the upper, middle and bottom boxes, respectively. This means that damage ratio, EBI, BAI and weight losses values increased and the firmness values decreased from bottom to upper boxes. According to O'Brien \& Guillou (1969), Singh \& Xu (1993) and Demir et al. (2010) this is because the bottom box usually receives the lowest acceleration level, and the upper box receives the highest acceleration level. Also, the fruits in the upper box can move freely as they receive sufficient energy from the bottom boxes. This result indicated that the input accelerations at the truck during transporting tomatoes were magnified in fruits in the upper boxes. During vibration, when the acceleration in the upper boxes exceed certain values, the fruits approach an unstable condition and begin to move freely as a result of energy received from fruits at lower levels. This causes the fruit at the top to be intermittently weightless and strike each 
other. However, the magnitude of vibration acceleration in the upper boxes during transit depends on the depth of fruits in the box, tightness of fill, type of suspension system used on the transport vehicle, magnitude of forced vibration transmitted from the real road and vibration characteristics of the fruit.

\subsection{Second-Order interactions between Vibration Frequency and Vibration Duration $($ VF $\times$ VD)}

The effect of vibration frequency levels on damage ratio, EBI, BAI, weight losses and firmness values in fresh tomato fruits at different vibration durations is shown in Figure (4) and (5). Vibration frequency of $7.5 \mathrm{~Hz}$ caused the highest damage ratio, EBI and BAI compared to the other vibration frequency levels. Also, it is noticed from Figure (4) and (5) that increasing vibration duration led to increasing all damage parameters (damage ratio, EBI and BAI) and weight losses and decreasing the firmness in tomatoes for all vibration frequency levels. This trend of result agrees with those reported by Fischer et al. (1992), Shahbazi et al. (2010) and Vursavuş \& Özgüven (2004). For example, the results revealed that increasing the vibration duration from 30 to 90 minutes increased the damage ratio from 7.13 to 10.56 , from 16.18 to 26.61, from 13.85 to 18.24 , from 7.00 to 11.25 and from 16.05 to $19.48 \%$ at vibration frequency levels of $5,7.5,10,12.5$ and $15 \mathrm{~Hz}$, respectively. Furthermore, the results shown in Figure (5) indicated that increasing the vibration duration from 30 to 90 minutes led to increasing the weight losses from 2.56 to 3.09 , from 3.73 to 7.11 , from 3.35 to 3.88 , from 2.77 to 3.22 and from 3.71 to $4.32 \%$ for the vibration frequency levels of 5, $7.5,10,12.5$ and $15 \mathrm{~Hz}$, respectively. On the other hand, increasing the vibration duration from 30 to 90 minutes led to decreasing the tomato firmness from 11.48 to 11.04 , from 8.90 to 7.08 , from 10.24 to 9.26 , from 10.73 to 10.19 and from 9.97 to $8.86 \mathrm{~N}$ for the vibration frequency levels of $5,7.5,10,12.5$ and $15 \mathrm{~Hz}$, respectively.

Figures (4) and (5) show also the least significant difference (LSD) tests performed to determine the differences among the mean values of the damage ratio, EBI, BAI, weight losses and firmness for the interaction between vibration frequency and vibration duration $(\mathrm{VF} \times \mathrm{VD})$. The LSD 
tests showed that there was a significant difference among the three vibration durations in damage ratio, EBI and weight losses values at vibration frequency of $7.5 \mathrm{~Hz}(\mathrm{P} \leq 0.05)$. However, there was no significant difference between vibration duration 30 and 60 min in BAI and firmness values at the vibration frequency of $7.5 \mathrm{~Hz}(\mathrm{P} \leq 0.05)$.
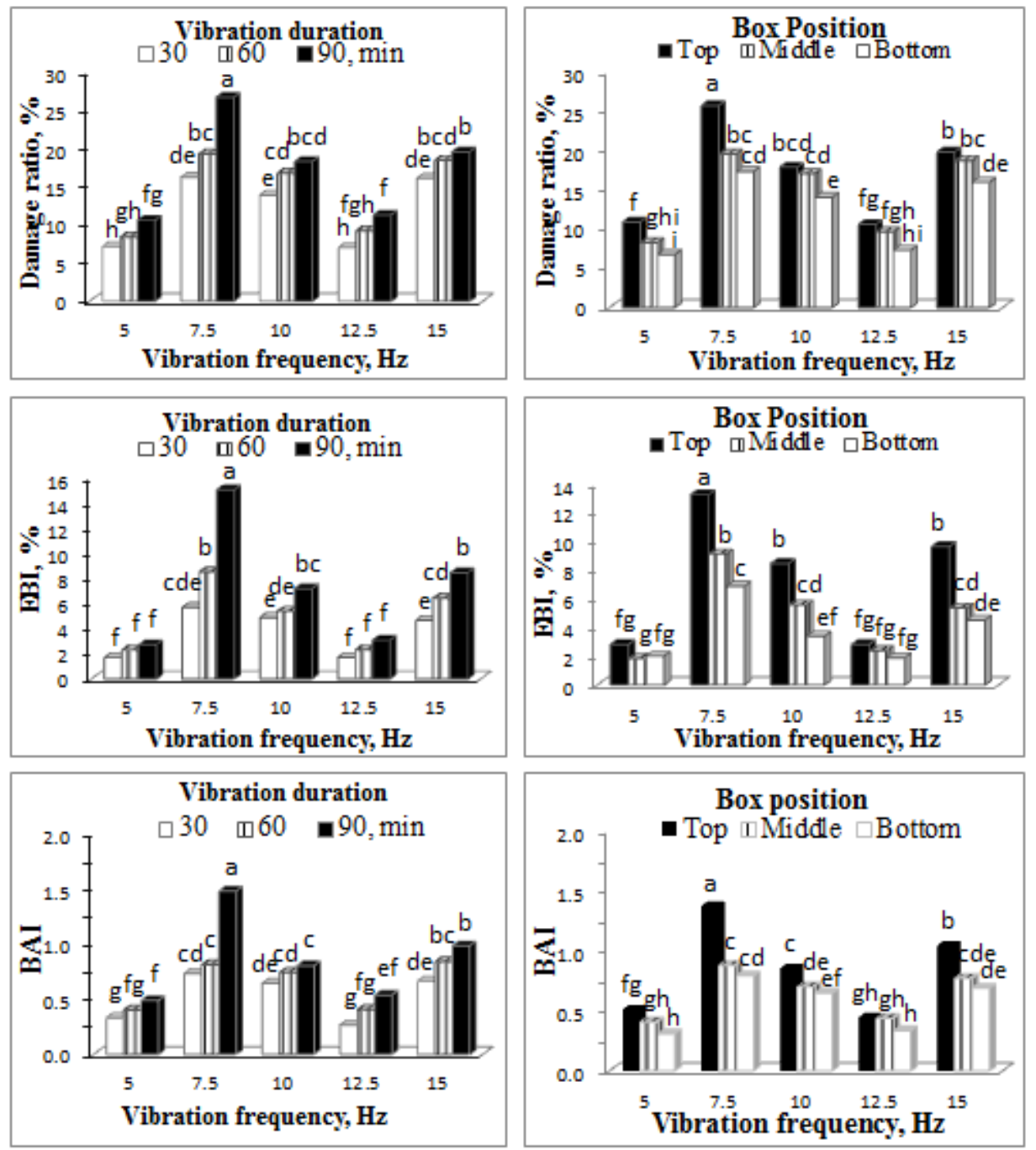

Figure (4): Effect of different vibration frequency levels on the average value damage ratio, EBI and BAI in fresh tomato fruits at different vibration durations and box positions.

The same letters above the bars means there is no significant difference $(p \leq 0.05)$. 
The results also showed that the lowest value of damage ratio and BAI values among the combinations of vibration frequency and vibration duration was $6.99 \%$ and 0.27 respectively, recorded at a vibration frequency of $12.5 \mathrm{~Hz}$ operated for $30 \mathrm{~min}$. However, the lowest value of EBI and weight losses values among the combinations was $1.69 \%$ and $2.56 \%$ at a vibration frequency of $5 \mathrm{~Hz}$ operated for $30 \mathrm{~min}$. On the contrary, the highest value of damage ratio, EBI, BAI and weight losses values among the combinations was $26.61 \%, 15.03 \%, 1.49$ and $7.11 \%$ respectively, recorded at $7.5 \mathrm{~Hz}$ for $90 \mathrm{~min}$. Also, the lowest value of tomato firmness among these combinations was $7.06 \mathrm{~N}$ at $7.5 \mathrm{~Hz}$ for 90 min. On the other hand, the highest value of tomato firmness among the combinations of vibration frequency and vibration duration was $11.48 \mathrm{~N}$ obtained at $5 \mathrm{~Hz}$ for $30 \mathrm{~min}$ as seen in Figure (4) and (5).

\subsection{Second-Order Interaction between Vibration Frequency and Box Position (VF $\times$ BP)}

Similar to the results observed in the interactions between vibration frequency and vibration duration, the data shown in Figure (4) and (5) indicated that fruits located at the upper box exhibited the highest value of damage ratio, EBI, BAI and weight losses and the lowest value of firmness compared with those located in the middle and bottom positions. In other words, the values of damage ratio, EBI, BAI and weight losses increased and the firmness decreased from bottom to upper boxes for all vibration frequency levels. This trend of result agreed with those obtained by Demir et al. (2010) and Aliasgarian et al. (2013). The results in Figure (4) showed that changing the box position from bottom to upper boxes increased the damage ratio from 6.72 to 10.84 , from17.01 to 25.65 , from 13.98 to 17.83 , from 7.27 to 10.56 and from 15.78 to $19.75 \%$ at vibration frequency levels of $5,7.5,10,12.5$ and $15 \mathrm{~Hz}$ respectively. Similar to the results found in the case of damage ratio, the results showed that changing the box position from bottom to upper boxes led to an increase in EBI values from 2.02 to 2.83 , from 6.87 to 13.25 , from 3.40 to 8.47 , from 1.90 to 2.81 and from 4.52 to $9.63 \%$ at the vibration frequency levels of $5,7.5,10,12.5$ and $15 \mathrm{~Hz}$, respectively. Also, the results showed that changing the box position from bottom to upper boxes led to an increase in BAI values from 0.31 to 0.51 , from 0.79 to 1.37 , 
from 0.65 to 0.85 , from 0.33 to 0.44 and from 0.69 to 1.04 at the vibration frequency levels of $5,7.5,10,12.5$ and $15 \mathrm{~Hz}$, respectively.

Moreover, the results in Figure (5) showed that changing the box position from bottom to upper boxes led to an increase in weight losses from 2.66 to 2.90 , from 4.20 to 6.56 , from 3.25 to 3.99 , from 2.89 to 3.13 and from 3.66 to $4.39 \%$ at vibration frequency levels of $5,7.5,10,12.5$ and $15 \mathrm{~Hz}$, respectively. Also, the results showed that changing the box position from bottom to upper boxes led to a decrease in tomato firmness from 11.68 to 10.87, from 9.02 to 7.21 , from 10.43 to 9.05 , from 10.67 to 10.20 and from 9.90 to $8.90 \mathrm{~N}$ at vibration frequency levels of 5, 7.5, 10, 12.5 and $15 \mathrm{~Hz}$, respectively.

Figures (4) and (5) showed the least significant difference (LSD) tests performed to determine the differences among the mean values of the damage ratio, EBI, BAI, weight losses and firmness for the interaction between vibration frequency and box position $(\mathrm{VF} \times \mathrm{BP})$. The LSD tests revealed that changing the box position had no significant effect on damage ratio and firmness $(\mathrm{P} \leq 0.05)$. However, changing the box position was significantly effective on the EBI, BAI and weight losses values $(\mathrm{P} \leq 0.05)$. Therefore, there was a significant difference among the three box positions in EBI and values at vibration frequency of $7.5 \mathrm{~Hz}$ or $10 \mathrm{~Hz}(\mathrm{P} \leq 0.05)$. However, there was no significant difference between the middle and bottom box in BAI and weight losses values at vibration frequency of $7.5 \mathrm{~Hz}$ or $10 \mathrm{~Hz}(\mathrm{P} \leq 0.05)$.

Generally, the results showed that the lowest value of damage ratio, BAI and weight losses values among the combinations of vibration frequency and box position was $6.72 \%, 0.31$ and $2.66 \%$, respectively at $5 \mathrm{~Hz}$ for bottom box. The lowest value of EBI values among the combinations was $1.86 \%$ at $5 \mathrm{~Hz}$ for the middle box. On the other hand, the highest value of damage ratio, EBI, BAI and weight losses values among the combinations was $25.65 \%, 13.25 \%, 1.37$ and $6.56 \%$, respectively at $7.5 \mathrm{~Hz}$ for the upper box as seen in Figure (4) and (5). Also, the lowest value of tomato firmness among the combinations was $7.21 \mathrm{~N}$ at $7.5 \mathrm{~Hz}$ at the upper box. However, the highest value of tomato firmness among the combinations of vibration frequency and box position was $11.68 \mathrm{~N}$ at $5 \mathrm{~Hz}$ at the bottom box as seen in Figure (5). 

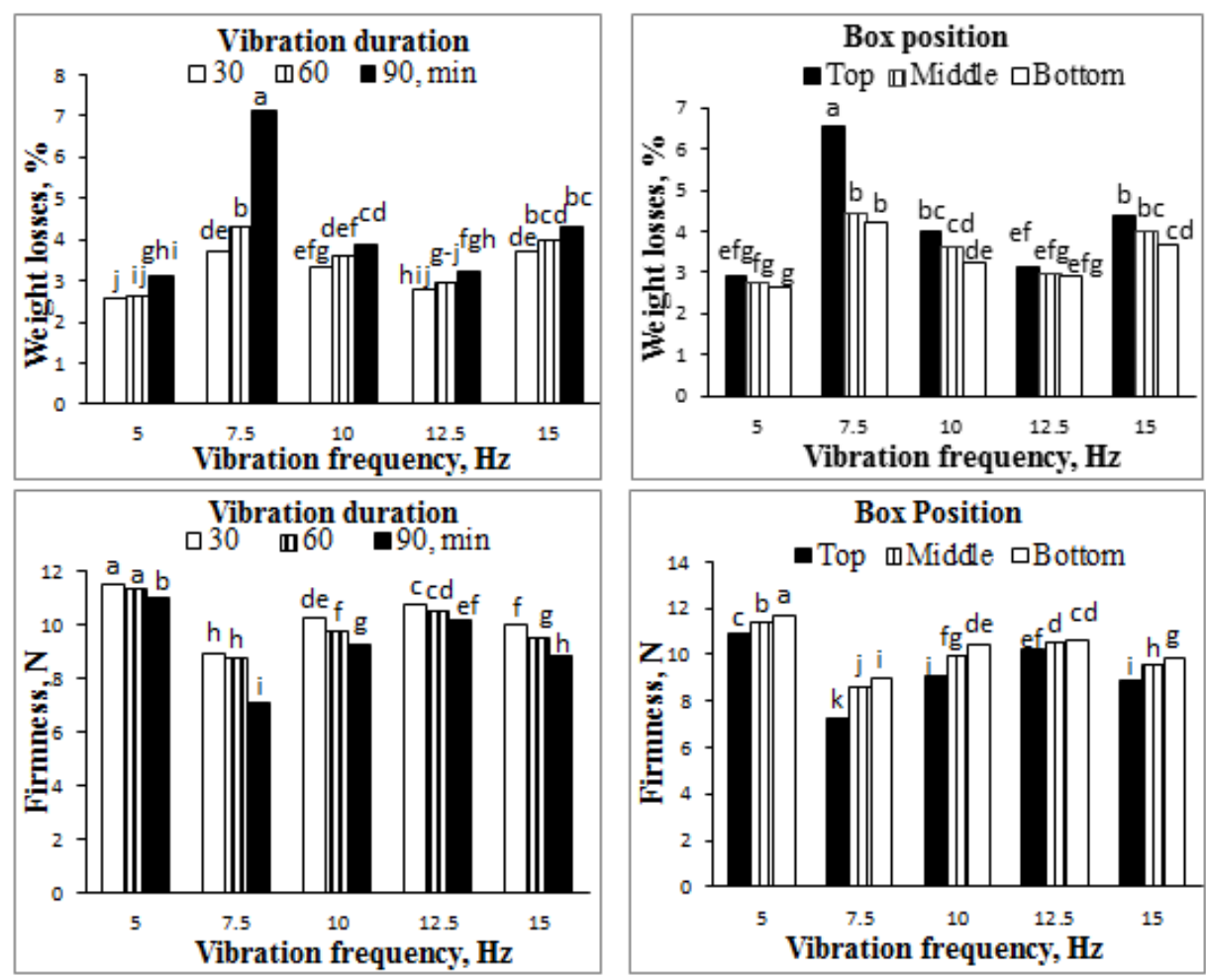

Figure (5): Effect of different vibration frequency levels on the average value of weight losses and firmness in fresh tomato fruits at different vibration durations and box positions.

The same letters above the bars means there is no significant difference $(p \leq 0.05)$.

\subsection{Third-Order Interaction between Vibration Frequency, Vibration Duration and Box Position $(\mathrm{VF} \times \mathrm{VD} \times \mathrm{BP})$}

The results in Table (3) indicated that there was no significant difference for the interaction between these three variables on damage ratio and BAI values in the tomato fruits. However, there was significant difference for the interaction between the three factors on EBI, weight losses and firmness. Moreover, the results in Table (5) show that the lowest value of damage ratio and EBI of $5.35 \%$ and $1.05 \%$ was obtained at the vibration frequency of $12.5 \mathrm{~Hz}$ and vibration duration of $30 \mathrm{~min}$ at the bottom box. Furthermore, the lowest value of BAI and weight losses was 0.22 and $2.44 \%$ when the vibration frequency of $5 \mathrm{~Hz}$ was operated for a vibration duration of $30 \mathrm{~min}$ at the bottom box. Also, the lowest value of tomato firmness was $5.83 \mathrm{~N}$ was obtained at the vibration frequency of $7.5 \mathrm{~Hz}$ for 
a vibration duration of $90 \mathrm{~min}$ at the upper box. On the other hand, the highest value of damage ratio, EBI, BAI and weight losses was $29.63 \%$, $20.75 \%, 2.15$ and $9.94 \%$, respectively when the vibration frequency was $7.5 \mathrm{~Hz}$ and the vibration duration was $90 \mathrm{~min}$ at the upper box. Also, the highest value of tomato firmness of $11.95 \mathrm{~N}$ was obtained at the vibration frequency of $5 \mathrm{~Hz}$ and the vibration duration of $30 \mathrm{~min}$ at the bottom box. Table (5): The lowest and the highest value of the damage ratio, EBI, BAI, weight losses and firmness for the interaction among the combinations of the studied variables $(\mathrm{VF} \times \mathrm{VD} \times \mathrm{BP})$.

\begin{tabular}{|c|c|c|}
\hline Variables & $\begin{array}{l}\text { Lowest value } \\
\text { (obtained at) }\end{array}$ & $\begin{array}{l}\text { Highest value } \\
\text { (obtained at) }\end{array}$ \\
\hline $\begin{array}{c}\text { Damage } \\
\text { ratio }\end{array}$ & $\begin{array}{c}5.35 \% \\
(12.5 \mathrm{~Hz}, 30 \mathrm{~min} \text { and bottom }) \\
\end{array}$ & $\begin{array}{c}29.63 \% \\
(7.5,90 \mathrm{~min} \text { and upper box })\end{array}$ \\
\hline EBI & $\begin{array}{c}1.05 \% \\
(12.5 \mathrm{~Hz}, 30 \mathrm{~min} \text { and bottom })\end{array}$ & $\begin{array}{c}20.75 \% \\
(7.5,90 \mathrm{~min} \text { and upper box }) \\
\end{array}$ \\
\hline BAI & $\begin{array}{c}0.22 \\
(12.5 \text { or } 5 \mathrm{~Hz}, 30 \mathrm{~min} \text { and bottom) }\end{array}$ & $\begin{array}{c}2.15 \\
(7.5,90 \mathrm{~min} \text { and upper box })\end{array}$ \\
\hline $\begin{array}{l}\text { Weight } \\
\text { losses }\end{array}$ & $\begin{array}{c}2.44 \% \\
(5 \mathrm{~Hz}, 30 \mathrm{~min} \text { and bottom }) \\
\end{array}$ & $\begin{array}{c}9.94 \% \\
(7.5,90 \mathrm{~min} \text { and upper box }) \\
\end{array}$ \\
\hline Firmness & $\begin{array}{c}5.83 \mathrm{~N} \\
(7.5,90 \mathrm{~min} \text { and upper box })\end{array}$ & $\begin{array}{c}11.95 \mathrm{~N} \\
(5 \mathrm{~Hz}, 30 \mathrm{~min} \text { and bottom })\end{array}$ \\
\hline
\end{tabular}

\section{SUMMARY AND CONCLUSIONS}

The main aim of this study was to determine the postharvest losses in tomato and identify the critical frequencies that cause minimum and maximum damage during transporting the product. Moreover, determining the effect of box position above the truck floor on the severity of the damage, firmness and weight losses of tomato. The summary of the results that have been obtained as follows:

- The values of damage ratio, EBI, BAI and weight losses increased and the firmness values decreased from the bottom to the upper boxes for all vibration frequency levels.

- Increasing the vibration duration led to increasing in damage ratio, EBI, BAI and weight losses in tomatoes and decreasing the tomato firmness value for all vibration frequency levels. 
- The analysis of variance results showed that the interaction effects of the $(\mathrm{VF} \times \mathrm{VD} \times \mathrm{BP})$ were significant on $\mathrm{EBI}$, weight loss and firmness values $(\mathrm{P} \leq 0.05)$. However, the interaction effects of the $(\mathrm{VF} \times \mathrm{VD} \times$ $\mathrm{BP})$ were not significant on damage ratio and BAI values $(\mathrm{P} \leq 0.05)$.

- The results revealed that the vibration frequency of $7.5 \mathrm{~Hz}$, vibration duration of 90 min and upper box caused the highest value of damage ratio, EBI, BAI and weight losses and the lowest value of firmness compared to the other vibration frequency levels.

\section{REFERENCES}

Aliasgarian, S.; Ghassemzadeh, H. R.; Moghaddam, M. \& Ghaffari, H. (2013). Mechanical Damage of Strawberry During Harvest and Postharvest Operations. World Applied Sciences Journal, 22(7):969-974.

Amer Eissa, A. H. \& Azam, M. M. (2011). Dynamic Behavior of Fresh Apple Fruit under Transport Conditions.1-19.

Bani, R.; Josiah, M. \& Kra, E. (2006). Postharvest Losses of Tomatoes in Transit. Agricultural mechanization in asia africa and latin america, 37(2):84.

Batu, A. (1998). Some Factors Affecting on Determination and Measurement of Tomato Firmness. Turk. J. Agric. For, 22:411-418.

Cao, S.; Hu, Z. \& Pang, B. (2010). Optimization of Postharvest Ultrasonic Treatment of Strawberry Fruit. Postharvest biology and technology, 55(3):150-153.

Demir, F.; kara, Z. \& Carman, K. (2010). Table Grapes Transport Simulation Study by Bardas (Vitis Vinifera L.) Cultivar Grown in Karaman Turkey.

Fischer, D.; Craig, W.; Watada, A.; Douglas, W. \& Ashby, B. (1992). Simulated in-Transit Vibration Damage to Packaged Fresh Market Grapes and Strawberries. Applied engineering in agriculture, 8(3):363-366.

Ghazavi, M. A.; Karami, R. \& Mahmoodi, M. (2012). Modeling Some Physico-Mechanical Properties of Tomato. Journal of Agricultural Science, 5(1):210-223.

Idah, P. A.; Yisa, M. G.; Ogbonnaya, C. \& Morenikeji, O. O. (2012). Simulated Transport Damage Study on Fresh Tomato 
(Lycopersicon Esculentum) Fruits. Agricultural Engineering International: CIGR Journal, 14(2):119-126.

Jing, Y.; Fu, M.-r.; Zhao, Y.-y. \& Mao, L.-c. (2009). Reduction of Chilling Injury and Ultrastructural Damage in Cherry Tomato Fruits after Hot Water Treatment. Agricultural Sciences in China, 8(3):304-310.

Jung, H.-M. \& Park, J.-G. (2012). Effects of Vibration Stress on the Quality of Packaged Apples During Simulated Transport. Journal of Biosystems Engineering, 37(1):44-50.

Kader, A. A. (2005). Increasing Food Availability by Reducing Postharvest Losses of Fresh Produce. International Postharvest Symposium 682:2169-2176.

Li, Z. \& Thomas, C. (2014). Quantitative Evaluation of Mechanical Damage to Fresh Fruits. Trends in Food Science \& Technology, 35(2):138-150.

Lü, E.; Lu, H.; Zhang, D.; Yang, Z. \& Liu, Y. (2010). Investigation and Analysis of Fruits and Vegetables Transportation. Pittsburgh, Pennsylvania, June 20-June 23, 2010: American Society of Agricultural and Biological Engineers:1.

Lu, F.; Ishikawa, Y.; Kitazawa, H. \& Satake, T. (2010). Impact Damage to Apple Fruits in Commercial Corrugated Fiberboard Box Packaging Evaluated by the Pressure-Sensitive Film Technique. Journal of Food, Agriculture and Environment, 8(2):132-136.

Mohsenin, N. N. (1986). Physical Properties of Plant and Animal Materials: Structure, Physical Characteristics and Mechanical Properties. Gordon and Breach Science Publ., New York, NY, USA., Vol. 1.: 20-841.

O'Brien, M. \& Bridley, R. (1970). Measurement of Vibrations Related to Harvesting and Handling of Fruits and Vegetables. Transactions of the ASABE [American Society of Agricultural and Biological Engineers], 13 (6):870-873.

O'Brien, M. \& Guillou, R. (1969). An in-Transit Vibration Simulator for Fruit-Handling Studies. Transactions of the ASABE [American Society of Agricultural and Biological Engineers], 12(1):94-97. 
O'Brien, M.; Gentry, J. P. \& Gibson, R. C. (1965). Vibrating Characteristics of Fruits as Related to in-Transit Injury. Transactions of the ASABE [American Society of Agricultural and Biological Engineers], 8(2):241-0243.

Rosa, S. (2006). Postharvest Management of Fruit and Vegetables in the Asia-Pacific Region/Asian Productivity Organization. Food and Agricultural Organization (FAO):15-307.

Rostampour, V.; Motlagh, A. M.; Komarizadeh, M. H.; Sadeghi, M.; Bernousi, I. \& Ghanbari, T. (2013). Using Artificial Neural Network (Ann) Technique for Prediction of Apple Bruise Damage. AJCS, 7(10):1442-1448.

Sadrnia, H.; Rajabipour, A.; Jafary, A.; Javadi, A. \& Mostofi, Y. (2007). Classification and Analysis of Fruit Shapes in Long Type Watermelon Using Image Processing. Int. J. Agric. Biol, 1(9):6870.

Shahbazi, F.; Rajabipour, A.; Mohtasebi, S. \& Rafie, S. (2010). Simulated in-Transit Vibration Damage to Watermelons. Journal of Agricultural Science and Technology, 12:23-34.

Singh, S. \& Xu, M. (1993). Bruising in Apples as a Function of Truck Vibration and Packaging. Applied engineering in agriculture, 9(5):455-460.

Timm, E.; Brown, G. \& Armstrong, P. (1996). Apple Damage in Bulk Bins During Semi-Trailer Transport. Applied engineering in agriculture (USA), 12(3):369-377.

Van Dijk, C.; Boeriu, C.; Peter, F.; Stolle-Smits, T. \& Tijskens, L. (2006). The Firmness of Stored Tomatoes (Cv. Tradiro). 1. Kinetic and near Infrared Models to Describe Firmness and Moisture Loss. Journal of Food Engineering, 77(3):575-584.

Vergano, P.; Testin, R. \& Newall Jr, W. (1991). Peach Bruising: Susceptibility to Impact, Vibration, and Compression Abuse. Transactions of the ASABE (USA), 34 (5):2110-2116.

Vursavuş, K. \& Özgüven, F. (2004). Determining the Effects of Vibration Parameters and Packaging Method on Mechanical Damage in Golden Delicious Apples. Turkish Journal of Agriculture and Forestry, 28(5):311-320. 


\title{
الملخص العربى
}

\section{تقدير بعض فو اقد ما بعد الحصاد فى الطماطم خلال محاكاة عملية النقل}

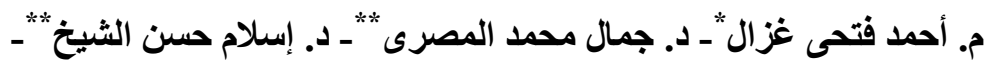

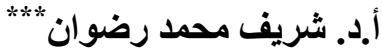

أُجريت هذه الدر اسة بهدف تقدير الضرر الميكانيكى الذى يحدث لمحصول الطهـاطم أثناء عملية

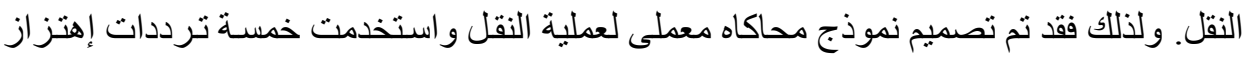

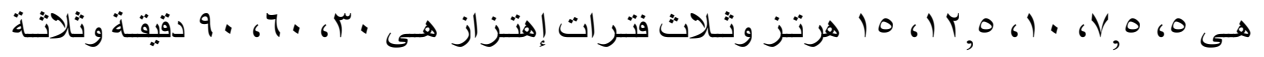

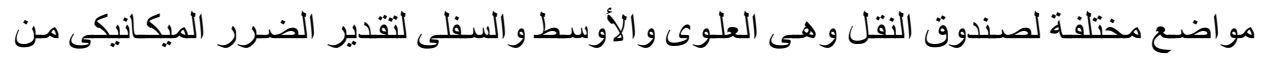

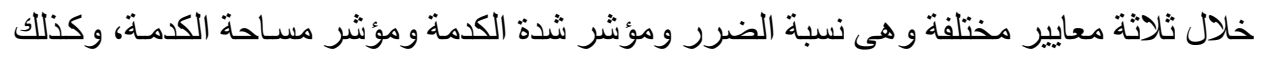

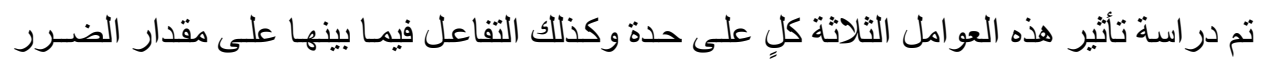

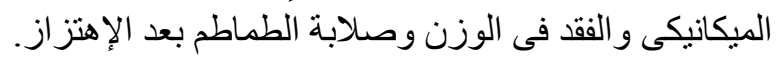

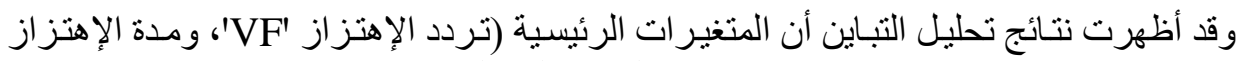

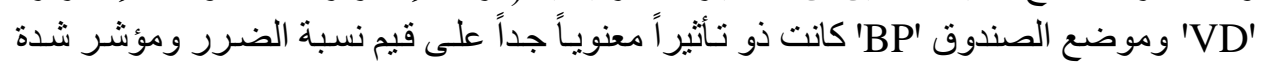

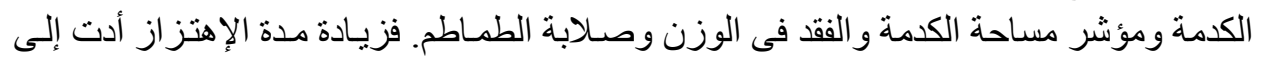

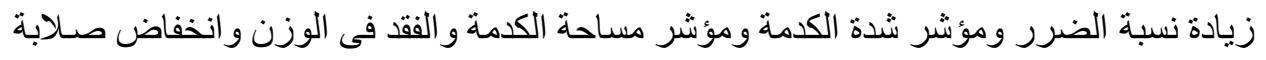

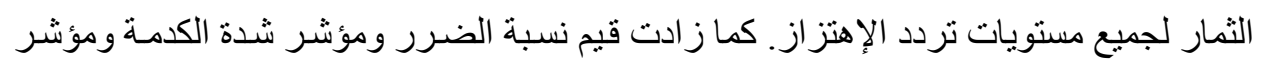

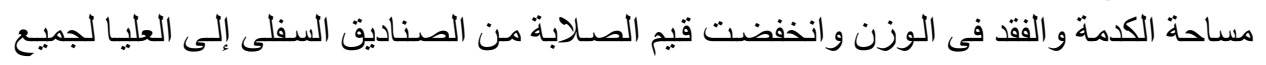

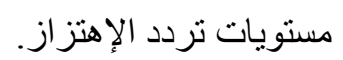

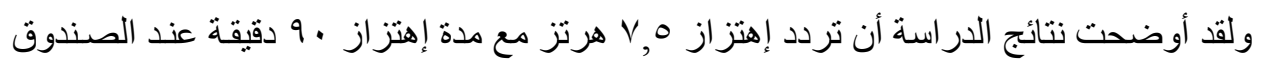

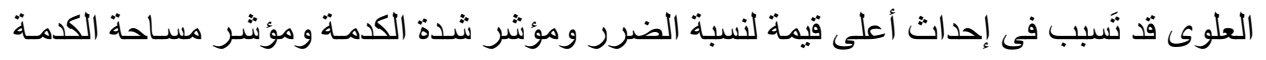

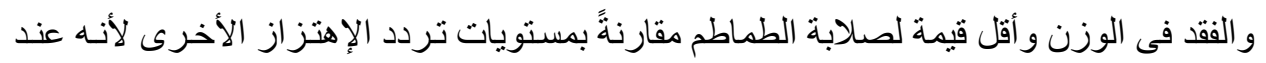

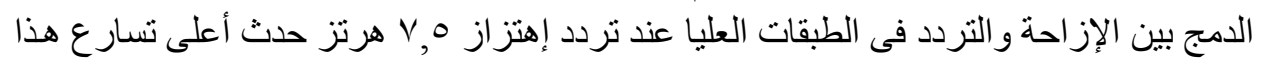

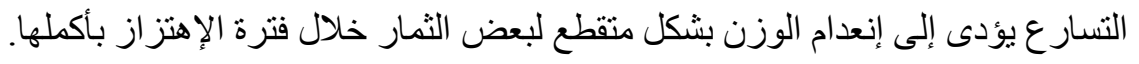

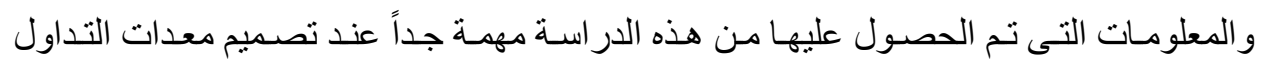

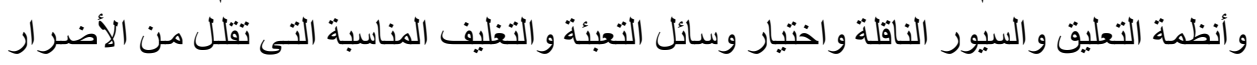

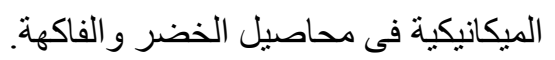

"معيد، ** أستاذ مساعد، *** أستاذ الهندسة الزراعية ـ قسم الهندسة الزراعية _ كلية الزراعة

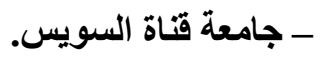

